\title{
Identification of NROB1 Gene Mutation and Analysis of Bone Damages and Drug Treatment Effect in a Big Family With X-linked Adrenal Hypoplasia Congenita: a Case Report
}

\section{XIAOHUI TAO}

Shanghai 6th Peoples Hospital Affiliated to Shanghai Jiaotong University School of Medicine LI LIU

Shanghai 6th Peoples Hospital Affiliated to Shanghai Jiaotong University School of Medicine XIAOYUN LIN

Shanghai 6th Peoples Hospital Affiliated to Shanghai Jiaotong University School of Medicine TIAN XU

Shanghai 6th Peoples Hospital Affiliated to Shanghai Jiaotong University School of Medicine HUA YUE ( $\square$ yueyinglonghua@163.com )

Shanghai 6th Peoples Hospital Affiliated to Shanghai Jiaotong University School of Medicine ZHENLIN ZHANG

Shanghai 6th Peoples Hospital Affiliated to Shanghai Jiaotong University School of Medicine

\section{Case report}

Keywords: adrenal hypoplasia congenita (AHC), hypogonadotropic hypogonadism (HHG), NR0B1, DAX-1, osteoporosis, treatment

Posted Date: April 1st, 2021

DOI: https://doi.org/10.21203/rs.3.rs-373516/v1

License: (c) (i) This work is licensed under a Creative Commons Attribution 4.0 International License. Read Full License 


\section{Abstract}

Background: $X$-linked congenital adrenocortical hypoplasia $(\mathrm{XL}-\mathrm{AHC})$ is a rare disorder, which is characterized by primary adrenal insufficiency and hypogonadotropic hypogonadism. However, the skeletal complications caused by the disease were rarely reported, not to mention the treatment.

Case presentation: The patient from a big family with XL-AHC was identified carrying a homozygous insertion mutation $\rrbracket$ p.Thr193GlyfsX13囚in $D A X-1$ gene. The diagnosis of secondary osteoporosis was made after imaging, laboratory and bone mass density examinations. However, he showed a suboptimal response to bisphosphonates during 2 years of follow-up, even suffered from atypical femoral fracture (AFF). Now it had been replaced by menatetrenone, bone healing was satisfactory.

Conclusions: We harbored the idea that clinicians should not only focus on typical clinical manifestations of XL-AHC, but also pay attention to the skeletal complications in clinical practice. Conventional antiosteoporosis drugs may cause side effects such as AFF and osteonecrosis of the jaw (ONJ), which was rare in general osteoporosis patients. In other words, anabolic agent may be a better choice.

\section{Background}

Adrenal hypoplasia congenita (AHC, OMIM300200) is a rare disorder, which has an approximately incidence of 1:12,500 live births in Australia[1]. Whereas the study from UK demonstrates the incidence rate of children is 1:140,000 1:1,200,000, among which male morbidity is 1:70,000 1:600,000[2]. AHC presents in two forms of histology, the miniature adult and the cytomegalic forms. The latter is inherited in an X-linked manner (XL-AHC), primarily affects males.

The onset age of AHC displays a "two-peak" profile[3], the majority are "early onset type", usually within 2 months of life, accompanied by severe salt-wasting and highly mortality[4]; onset at 2-9 years old are "late onset type", for which clinical symptoms are more atypical and insidious[3,5]. Affected subjects usually present with primary adrenal insufficiency (PAI) at an early age, accompanied with or without hypogonadotropic hypogonadism (HHG). AHC can also occur as portion of the Xp21 deletion syndrome, including the phenotypes of Glycerol kinase deficiency (GKD), Duchenne muscular dystrophy (DMD), and mental retardation[6,7]. Increased levels of plasma adrenocorticotropic hormone (ACTH), reduction of cortisol and aldosterone, hyponatremia and hyperkalemia are the most common laboratory abnormalities[1,3].

Mutations in NR0B1 gene mapped on chromosome Xp21 are responsible for the XL-AHC[3]. NROB1 encodes DAX-1 protein, which is mainly expressed in the steroidogenic tissue (gonads and adrenal cortex), as well as hypothalamus and pituitary[8]. It plays an essential role for the development and regulation of functioning adrenal gland and reproductive axis.

Most previous studies concerned about the typical clinical symptoms, such as PAI and HHG in patients with $\mathrm{AHC}$, yet the skeletal complications caused by the disease were overlooked. In the present study, the 
AHC patient with severe osteoporosis was followed up for two years, to our astonishment was that he showed a suboptimal response to bisphosphonates, even suffered from atypical femoral fracture (AFF) during the treatment. Based on the above data, we summarized and discussed the clinical features, bone complications and drug treatment of the patient with AHC, in order to yield deeper understanding of the disease, further explore the individualized treatment of such patients with secondary osteoporosis.

\section{Case Presentation}

Here we investigated one patient from a Chinese family suffered from AHC (Fig. 1) who came to our department.

The index individual III8 (Fig. 1), a 49-yr-old male of non-consanguineous Chinese parents, was born at full term with a birth weight of $3600 \mathrm{~g}$ and milestones were normal. By age 8 , he developed recurrent episodes of fever, chills and fatigue for unknown causes. Skin hyperpigmentation was noticed at the same time and progressed over the years, especially in lip, ear and finger joints. Besides, he presented delayed growth and no change of voice in comparison with age-matched reference range group at puberty. He was diagnosed as "primary adrenal insufficiency" (specific data was not available) at the local hospital, and treated with prednisone for nearly 30 years, the maximum dose up to $30 \mathrm{mg} /$ day. Since then, he experienced two acute adrenal crisis owing to drug withdrawal. At the age of 42 he developed backache, fatigue and muscle twitch, a diagnosis of HHG and osteoporosis were made based on decreased sexual hormone level and low bone mass density (BMD), respectively. He also complained of hyposexuality and erectile dysfunction. After receiving oral testosterone undecanoate 6 years and alendronate for 3 years, yet intermittently, his sexual function recovered slightly. However, there was no sign of improvement on back pain, hence he was admitted to our hospital.

Although detailed data was not available, it is known that III14,15,18,19,20 from the family all manifested the same phenotypes as the patient, such as pigmentation, salt-wasting or infertility, and died between the ages of 7 and 11. The other individual (V1) who survived with clinical manifestations showed weight loss and progressive skin pigmentation.

His height is $158 \mathrm{~cm}$ and weight is $50 \mathrm{~kg}$, fingertip distance is $168 \mathrm{~cm}$. Physical examination revealed moderate hyperpigmentation in buccal mucosa, lips and gum. Sparse secondary sexual hair and small penis were presented (Tanner stage II), along with low testicular volume of $4 \mathrm{ml}, 5 \mathrm{ml}$ on left and right, respectively. Cerebral MRI was normal. X-ray reveals multiple compression fractures of thoracolumbar spine, and the abdominal CT scan revealed small non-calcified adrenal glands (Fig. 3). ECT showed multiple radioactive concentration. DXA revealed a low BMD (L1-L4: Z-score - 2.3SD, Femoral neck: Zscore - 2.2SD, Total hip: Z-score - 2.6SD). Results of lab tests were summarized in Table 1. 
Table 1

Basic laboratory findings in patient with $\mathrm{AHC}$

\begin{tabular}{|lll|}
\hline Indicator & Patient & Normal adult values \\
\hline $\mathrm{Na}+(\mathrm{mmol} / \mathrm{l})$ & 139 & $135 \sim 145$ \\
\hline $\mathrm{K}+(\mathrm{mmol} / \mathrm{l})$ & 3.9 & $3.5 \sim 5.5$ \\
\hline $\mathrm{Ca}+(\mathrm{mmol} / \mathrm{L})$ & 2.35 & $2.08 \sim 2.60$ \\
\hline P- (mmol/L) & 1.31 & $0.80 \sim 1.60$ \\
\hline Cortisol at 08:00 h ( $\mu \mathrm{g} / \mathrm{dL})$ & 1.19 & $6.20 \sim 19.4$ \\
\hline ACTH (ng/L) & 117.20 & $7.2 \sim 63.3$ \\
\hline PRC supine at 08:00 ( $\mu$ lU/mL) & $>500.0$ & $2.8 \sim 39.9$ \\
\hline Angll (pg/mL) & 189 & $25-60$ \\
\hline ALD supine at 08:00 (ng/dL) & 2.29 & $1.17 \sim 23.6$ \\
\hline T (nmol/L) & 3.82 & $8.40 \sim 28.70$ \\
\hline LH (IU/L) & 0.26 & $1.4 \sim 18.1$ (male 13-70 y) \\
\hline FSH (IU/L) & 5.79 & $1.5 \sim 9.3$ (male 20-70 y) \\
\hline OGTT 2h (nmol/L) & 3.66 & $3.90-7.80$ \\
\hline B-CTX (ng/l) & 450.5 & $<584$ (male 30-50 y) \\
\hline OC (ng/ml) & 15.5 & $14 \sim 42$ (male 30-50 y) \\
\hline 25OHD (ng/mL) & 29.91 & $>20$ \\
\hline ALP (U/L) & 114 & $15-112$ \\
\hline PTH (pg/ml) & 6.39 & $15.00 ~ 65.00$ \\
\hline $\begin{array}{l}\text { ABBERVATIONS: ACTH: adrenocorticotropic hormone; PRC: plasma renin concentration; Angll: } \\
\text { angiotensin Il; ALD: aldosterone; T: testosterone; LH: luteinizing hormone; FSH: follicle-stimulating }\end{array}$ \\
hormone; OGTT 2h: 2 hours after a 75-g oral glucose tolerance test; $\beta$-CTX: $\beta$-isomerized C-terminal \\
telopeptide of type I collagen; OC: osteocalcin; ALP: alkaline phosphatase; PTH: parathyroid hormone \\
\hline
\end{tabular}

Sanger sequencing of NROB1 revealed an inserted mutation (c.572_575dup) in exon 1, resulting in a frameshift with premature termination (p.Thr193GlyfsX13). Unfortunately, other individuals with AHC clinical symptoms from the family were not confirmed by gene detection.

The diagnosis of osteoporosis was made after a series of tests, accompanied with high bone turnover activity. Given the intermittent use of bisphosphonates may bring about poor efficacy, a regular oral alendronate treatment (70 mg, Alendronate Sodium and Vitamin D3 Tablets, Merck Sharp \& Dohme Ltd, 
USA) was advised. However, re-laboratory data revealed the high level of bone turnover one year later. Therefore, we recommended the patient received intravenous zoledronate ( $5 \mathrm{mg}$, Aclasta, Novartis Pharma Stein AG, Switzerland) yearly. Disappointedly, he was followed up in outpatient clinic regularly and showed poor response to both two drugs according to the continuous high bone metabolism index. Significantly, he suffered two fractures during treatment (Fig. 4). Now it had been replaced by menatetrenone, bone healing was satisfactory. Laboratory studies during follow-up were showed in Table 2.

Table 2

Markers of bone metabolism during the treatment with anti-osteoporosis drug

\begin{tabular}{|c|c|c|}
\hline Follow up & $\beta-C T X(n g / l)$ & $\mathrm{OC}(\mathrm{ng} / \mathrm{ml})$ \\
\hline First visit ${ }^{a}$ & 411.10 & 21.06 \\
\hline 4 months later & 475.80 & 18.01 \\
\hline 8 months later & 572.50 & 19.87 \\
\hline 12 months later ${ }^{b}$ & 516.00 & 17.36 \\
\hline 14 months later ${ }^{c}$ & - & - \\
\hline 20 months later ${ }^{d}$ & - & - \\
\hline 21 months later ${ }^{e}$ & 501.00 & 12.26 \\
\hline 24 months later & 527.5 & 33.55 \\
\hline \multicolumn{3}{|c|}{$\beta$-CTX: $\beta$-isomerized C-terminal telopeptide of type I collagen; OC: osteocalci } \\
\hline \multicolumn{3}{|c|}{${ }^{a}$ He was treated with alendronate orally. } \\
\hline \multicolumn{3}{|c|}{${ }^{\mathrm{b}}$ He was treated with a single infusion of intravenous zoledronic acid. } \\
\hline \multicolumn{3}{|c|}{${ }^{\mathrm{c}}$ Right femur fracture occurred from walking by a fall. } \\
\hline \multicolumn{3}{|c|}{ d Atypical fracture of left femur occurred of unknown causes. } \\
\hline e He was treated w & ne orally. & \\
\hline
\end{tabular}

\section{Discussion And Conclusions}

AHC is a special type of primary adrenal insufficiency (PAI), which was first documented by the pathologist Sikl in 1948[4]. In 1994, Muscatelli et al. found the candidate gene was localized at the Xp21.3 region, whose mutation or deletion results in $\mathrm{AHC}[6]$. The NROB1 gene consists of 2 exons separated by a 3385bp intron and encodes a 470 amino acid DAX-1 protein, an unusual member of the nuclear hormone-receptor superfamily[9]. The N-terminal of DAX-1 is absence of highly conserved zinc 
finger DNA binding domain (DBD) of the classical nuclear receptor, replaced by a 65-70 amino acid motif consisting of 3.5 alanine/glycine-rich repeats[10], which plays a vital role in the transcription regulation of NROB1 [11,12]. The C-terminal domain of DAX-1 protein is similar to the Ligand-binding Domain (LBD) of the nuclear receptor superfamily[10], which successfully applies to selectivity and specificity ability of physiological activities[13].

Over 300 individuals and families with XL-AHC had been reported previously, most of which were frameshift or nonsense mutations[14-18]. It is speculated that the hot spot mutation of NROB1 located in the putative LBD[2,18], causing premature truncation of the DAX1 protein.

It has been described that the age of onset and clinical features caused by the same NROB1 mutation are different [19], and the phenotype of patients with AHC was variable. In the present pedigree, affected individuals manifested various clinical phenotypes from the detailed history, which is concordant with previous studies $[19,20]$. This phenomenon suggested genetic heterogeneity and epigenetic factors were paramount in prognosis of AHC. However, it's a pity we were unable to obtain detailed data of the other patients from the extended family. In the near future, studies were required to reveal the complex genotype-phenotype correlation.

The patient reported here presented with the classical, late-onset clinical and endocrine characteristics, subsequent direct DNA sequencing supported the diagnosis with XL-AHC. In addition, the constructed family tree was consistent with X-linked recessive inheritance, accordingly we speculated that female was the heterozygous carrier of this mutation and male was the patient with XL-AHC. We hypothesized that undiagnosed adrenal crisis was the cause of early death in these male patients. Furthermore, severe osteoporosis was induced by the lack of multitude of hormones, especially androgen. Long term corticosteroid replacement therapy may also have an adverse impact on BMD. Previous studies had described $\mathrm{HH}$ patients accompanied with osteoporosis or osteopenia[21,7], yet even sufficient androgen substitution didn't reverse bone loss[22]. However, there is a shortage of follow-up data of osteoporosis treatment. Our study was the first follow-up study of osteoporosis in AHC patients.

Interestingly, Most of osteoporosis patients responded well to alendronate or zoledronate[23]. In contract, long-term high bone turnover marker concentrations (OC and $\beta$-CTX) in the subject with AHC indicating that bisphosphonates treatment either in oral or intravenous routes failed to suppress bone resorption. More seriously, AFF occurred during the treatment, which was is extremely rare in Asian patients with osteoporosis[24,25]. There were several speculations behind the above-mentioned phenomenon. In the first place, the patient himself was resistance to bisphosphonates. Secondly, the mutation site c.572_575dup in NROB1 gene had a certain effect on bone metabolism, which may promote osteoclast activity and enhance bone resorption through unknown mechanism. Thirdly, bone metabolic markers can not evaluate the effectiveness of bisphosphonates properly. With regard to the above assumptions, we need to perform pharmacogenomics analysis and functional research both in vitro and in vivo in the near future. 
The therapies for $\mathrm{AHC}$ were mainly maintenance of hormone replacement and symptomatic treatment, affected boys with HHG required androgen replacement therapy before pubertal to develop secondary sexual characteristics and improve the quality of life. Since previous studies demonstrated that sufficient testosterone replacement did not reverse the decreased bone mass associated with hypogonadism after adolescence $[22,26]$, we harbored the idea that bone health of AHC patients should be paid attention to before skeletal maturation. Owing to the long-term low bone mass, it is necessary to monitor the course of treatment, dosage and drug type when using anti-osteoporotic drugs (especially bisphosphonates) to avoid side effects such as AFF and osteonecrosis of the jaw (ONJ).

In conclusion, the present study summarized clinical features of the patient suffered AHC and bone complications, followed him up for two years by regular visits. From our part, clinicians should not only focus on the treatment of typical clinical manifestations, but also pay attention to the skeletal complications in clinical practice. Besides, we emphasized the importance of an assessment of bone mass, treatment with replacement therapy or a specific treatment for osteoporosis at an earlier age should be considered, also, dosage and course of treatment should be monitored in time. In other words, anabolic agent may be a better choice.

\section{Abbreviations}

XL-AHC: X-linked congenital adrenocortical hypoplasia

PAl: primary adrenal insufficiency

HHG: hypogonadotropic hypogonadism

GKD: Glycerol kinase deficiency

DMD: Duchenne muscular dystrophy

ACTH: adrenocorticotropic hormone

AFF: atypical femoral fracture

CT: computed tomograph

MRI: magnetic resonance

ECT: 99m Tc bone scanning with SPECT

BMD: bone mass density

DXA: dual-energy X-ray absorptiometry

osteonecrosis of the jaw (ONJ). 


\section{Declarations}

\section{Ethics approval and consent to participate}

Approval was obtained from the Ethics Committee of the Shanghai Jiao Tong University Affiliated the Sixth People's Hospital. The procedures used in this study adhere to the tenets of the Declaration of Helsinki.

\section{Consent for publication}

Written informed consent was obtained from the patient for publication of this case report and accompanying images. A copy of the written consent is available for review by the Editors-in-Chief of this journal.

\section{Availability of data and materials}

The datasets used and/or analysed during the current study are available from the corresponding author on reasonable request.

\section{Competing interests}

The authors declare that they have no competing interests.

\section{Funding}

This work was supported by grant from the National Natural Science Foundation of China (Grant No. 81770874, 81974126), Shanghai Natural Science Foundation (Grant No.16ZR1425700) and the Shanghai Municipal Key Clinical Specialty.

\section{Authors' contributions}

XT analyzed, interpreted the patient data and drafted the manuscript. LL, XL and TX collected clinical data and blood samples. HY and ZZ revised the manuscript. All authors contributed to manuscript revision, read, and approved the submitted version.

\section{Acknowledgements}

We gratefully acknowledge all colleagues in the Shanghai Sixth People's Hospital affiliated to Shanghai Jiao Tong University for their support and efforts put in this study and all the subjects for their participation.

\section{References}

1. Laverty, C.R.A., Fortune, D.W., Beischer, N.A.: Congenital idiopathic adrenal hypoplasia. Obstetrics \& Gynecology 41(5), 655-664 (1973). 
2. Lin, L., Gu, W.X., Ozisik, G., To, W.S., Owen, C.J., Jameson, J.L., Achermann, J.C.: Analysis of DAX1 (NR0B1) and steroidogenic factor-1 (NR5A1) in children and adults with primary adrenal failure: ten years' experience. J Clin Endocrinol Metab 91(8), 3048-3054 (2006). doi:10.1210/jc.2006-0603

3. Reutens, A.T., Achermann, J.C., Ito, M., Ito, M., Gu, W.X., Habiby, R.L., Donohoue, P.A., Pang, S., Hindmarsh, P.C., Jameson, J.L.: Clinical and functional effects of mutations in the DAX-1 gene in patients with adrenal hypoplasia congenita. J Clin Endocrinol Metab 84(2), 504-511 (1999). doi:10.1210/jcem.84.2.5468

4. Sikl, H.: Addison's disease due to congenital hypoplasia of the adrenals in an infant aged 33 days. J Pathol Bacteriol 60(2), 323 (1948). doi:10.1002/path.1700600220

5. Kyriakakis, N., Shonibare, T., Kyaw-Tun, J., Lynch, J., Lagos, C.F., Achermann, J.C., Murray, R.D.: Lateonset X-linked adrenal hypoplasia (DAX-1, NROB1): two new adult-onset cases from a single center. Pituitary 20(5), 585-593 (2017). doi:10.1007/s11102-017-0822-x

6. Muscatelli, F., Strom, T.M., Walker, A.P., Zanaria, E., Récan, D., Meindl, A., Bardoni, B., Guioli, S., Zehetner, G., Rabl, W., et al.: Mutations in the DAX-1 gene give rise to both $\mathrm{X}$-linked adrenal hypoplasia congenita and hypogonadotropic hypogonadism. Nature 372(6507), 672-676 (1994). doi:10.1038/372672a0

7. Francke, U., Harper, J.F., Darras, B.T., Cowan, J.M., McCabe, E.R., Kohlschütter, A., Seltzer, W.K., Saito, F., Goto, J., Harpey, J.P., et al.: Congenital adrenal hypoplasia, myopathy, and glycerol kinase deficiency: molecular genetic evidence for deletions. Am J Hum Genet 40(3), 212-227 (1987).

8. Guo, W.W., Burris, T.P., Mccabe, E.R.B.: Expression of DAX-1, the Gene Responsible for X-Linked Adrenal Hypoplasia Congenita and Hypogonadotropic Hypogonadism, in the Hypothalamic-PituitaryAdrenal/Gonadal Axis. Biochemical \& Molecular Medicine 56(1), 8-13 (1995).

9. Guo, W., Burris, T.P., Zhang, Y.H., Huang, B.L., Mason, J., Copeland, K.C., Kupfer, S.R., Pagon, R.A., McCabe, E.R.: Genomic sequence of the DAX1 gene: an orphan nuclear receptor responsible for Xlinked adrenal hypoplasia congenita and hypogonadotropic hypogonadism. J Clin Endocrinol Metab 81(7), 2481-2486 (1996). doi:10.1210/jcem.81.7.8675564

10. Burris, T.P., Guo, W., McCabe, E.R.: The gene responsible for adrenal hypoplasia congenita, DAX-1, encodes a nuclear hormone receptor that defines a new class within the superfamily. Recent Prog Horm Res 51, 241-259; discussion 259-260 (1996).

11. García-Acero, M., Molina, M., Moreno, O., Ramirez, A., Forero, C., Céspedes, C., Prieto, J.C., Pérez, J., Suárez-Obando, F., Rojas, A.: Gene dosage of DAX-1, determining in sexual differentiation: duplication of DAX-1 in two sisters with gonadal dysgenesis. Mol Biol Rep 46(3), 2971-2978 (2019). doi:10.1007/s11033-019-04758-y

12. Lalli, E.: Role of Orphan Nuclear Receptor DAX-1/NR0B1 in Development, Physiology, and Disease. Advances in Biology 2014, 582749 (2014). doi:10.1155/2014/582749

13. Mangelsdorf, D.J., Thummel, C., Beato, M., Herrlich, P., Schütz, G., Umesono, K., Blumberg, B., Kastner, P., Mark, M., Chambon, P., Evans, R.M.: The nuclear receptor superfamily: the second decade. Cell 83(6), 835-839 (1995). doi:10.1016/0092-8674(95)90199-x 
14. Habiby, R.L., Boepple, P., Nachtigall, L., Sluss, P.M., Crowley, W.F., Jr., Jameson, J.L.: Adrenal hypoplasia congenita with hypogonadotropic hypogonadism: evidence that DAX-1 mutations lead to combined hypothalmic and pituitary defects in gonadotropin production. J Clin Invest 98(4), 10551062 (1996). doi:10.1172/jci118866

15. Li, N., Liu, R., Zhang, H., Yang, J., Sun, S., Zhang, M., Liu, Y., Lu, Y., Wang, W., Mu, Y., Ning, G., Li, X.: Seven novel DAX1 mutations with loss of function identified in Chinese patients with congenital adrenal hypoplasia. J Clin Endocrinol Metab 95(9), E104-111 (2010). doi:10.1210/jc.2009-2408

16. Krone, N., Riepe, F.G., Dörr, H.G., Morlot, M., Rudorff, K.H., Drop, S.L., Weigel, J., Pura, M., Kreze, A., Boronat, M., de Luca, F., Tiulpakov, A., Partsch, C.J., Peter, M., Sippell, W.G.: Thirteen novel mutations in the NR0B1 (DAX1) gene as cause of adrenal hypoplasia congenita. Hum Mutat 25(5), 502-503 (2005). doi:10.1002/humu.9331

17. Buonocore, F., Achermann, J.C.: Primary adrenal insufficiency: New genetic causes and their longterm consequences. Clin Endocrinol (Oxf) 92(1), 11-20 (2020). doi:10.1111/cen.14109

18. Goodfellow, P.N., Camerino, G.: DAX-1, an 'antitestis' gene. Cell Mol Life Sci 55(6-7), 857-863 (1999). doi:10.1007/pl00013201

19. Wu, S.M., Gao, J.Z., He, B., Long, W.J., Luo, X.P., Chen, L.: A Novel NR0B1 Gene Mutation Causes Different Phenotypes in Two Male Patients with Congenital Adrenal Hypoplasia. Curr Med Sci 40(1), 172-177 (2020). doi:10.1007/s11596-020-2161-9

20. Laissue, P., Copelli, S., Bergada, I., Bergada, C., Barrio, G., Karaboga, S., Wurtz, J.M., Fellous, M., Lalli, E., Veitia, R.A.: Partial defects in transcriptional activity of two novel DAX-1 mutations in childhoodonset adrenal hypoplasia congenita. Clin Endocrinol (Oxf) 65(5), 681-686 (2006). doi:10.1111/j.1365-2265.2006.02649.x

21. Simsek-Kiper, P.O., Dikoglu, E., Campos-Xavier, B., Utine, G.E., Bonafe, L., Unger, S., Boduroglu, K., Superti-Furga, A.: Positive effects of an angiotensin II type 1 receptor antagonist in CamuratiEngelmann disease: a single case observation. Am J Med Genet A 164a(10), 2667-2671 (2014). doi:10.1002/ajmg.a.36692

22. De Rosa, M., Paesano, L., Nuzzo, V., Zarrilli, S., Del Puente, A., Oriente, P., Lupoli, G.: Bone mineral density and bone markers in hypogonadotropic and hypergonadotropic hypogonadal men after prolonged testosterone treatment. J Endocrinol Invest 24(4), 246-252 (2001). doi:10.1007/bf03343854

23. Eastell, R., Szulc, P.: Use of bone turnover markers in postmenopausal osteoporosis. Lancet Diabetes Endocrinol 5(11), 908-923 (2017). doi:10.1016/s2213-8587(17)30184-5

24. Iba, K., Takada, J., Sonoda, T., Yamashita, T.: Effect of continuous long-term treatment for 10 years with bisphosphonate on Japanese osteoporosis patients. J Bone Miner Metab 38(2), 240-247 (2020). doi:10.1007/s00774-019-01049-1

25. Black, D.M., Geiger, E.J., Eastell, R., Vittinghoff, E., Li, B.H., Ryan, D.S., Dell, R.M., Adams, A.L.: Atypical Femur Fracture Risk versus Fragility Fracture Prevention with Bisphosphonates. N Engl J Med 383(8), 743-753 (2020). doi:10.1056/NEJMoa1916525 
26. Wong, F.H., Pun, K.K., Wang, C.: Loss of bone mass in patients with Klinefelter's syndrome despite sufficient testosterone replacement. Osteoporos Int 3(1), 3-7 (1993). doi:10.1007/bf01623169

\section{Figures}

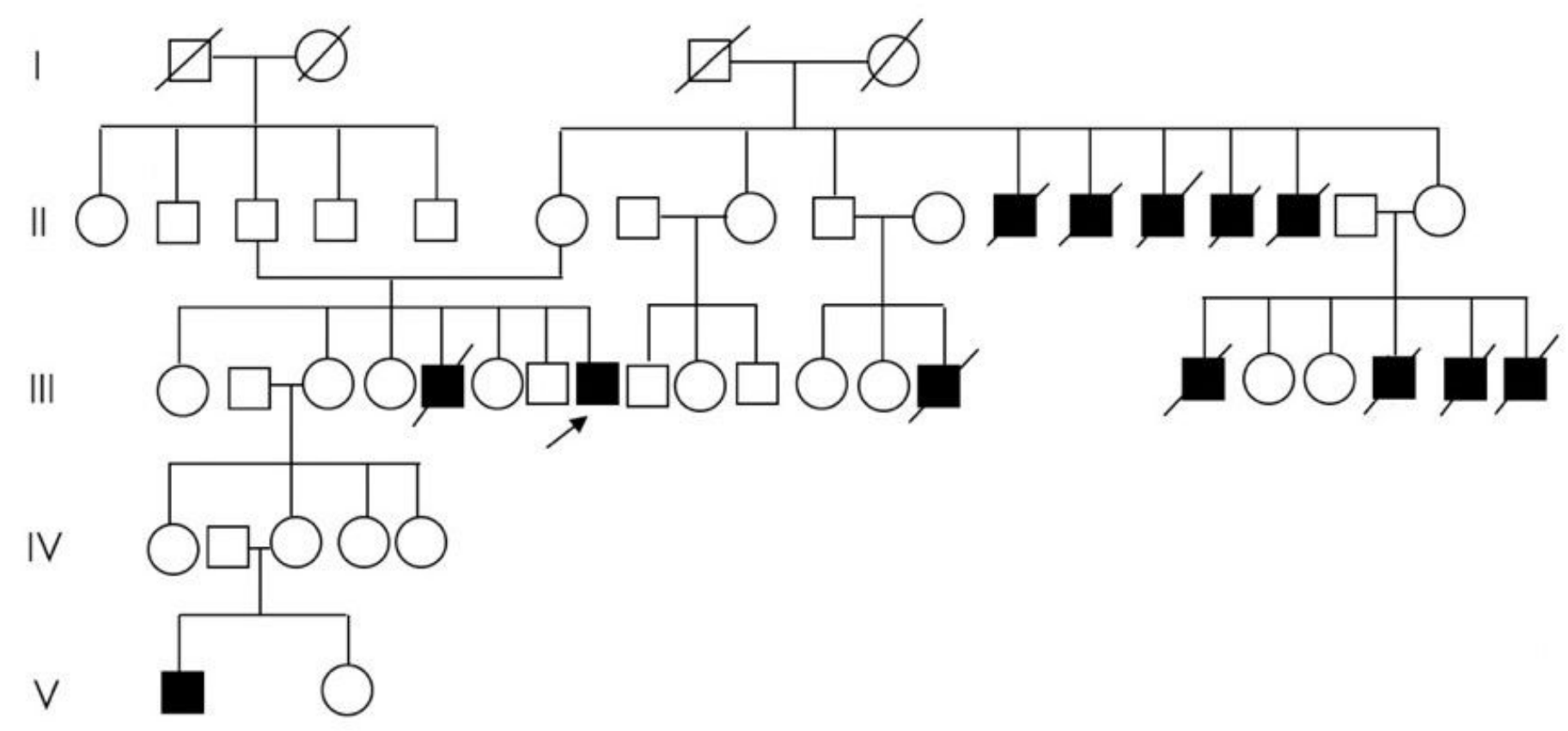

Figure 1

Pedigree of the family in the present study. Patients with typical clinical symptoms of AHC were shown by darkened symbols. The black arrow indicated the proband.

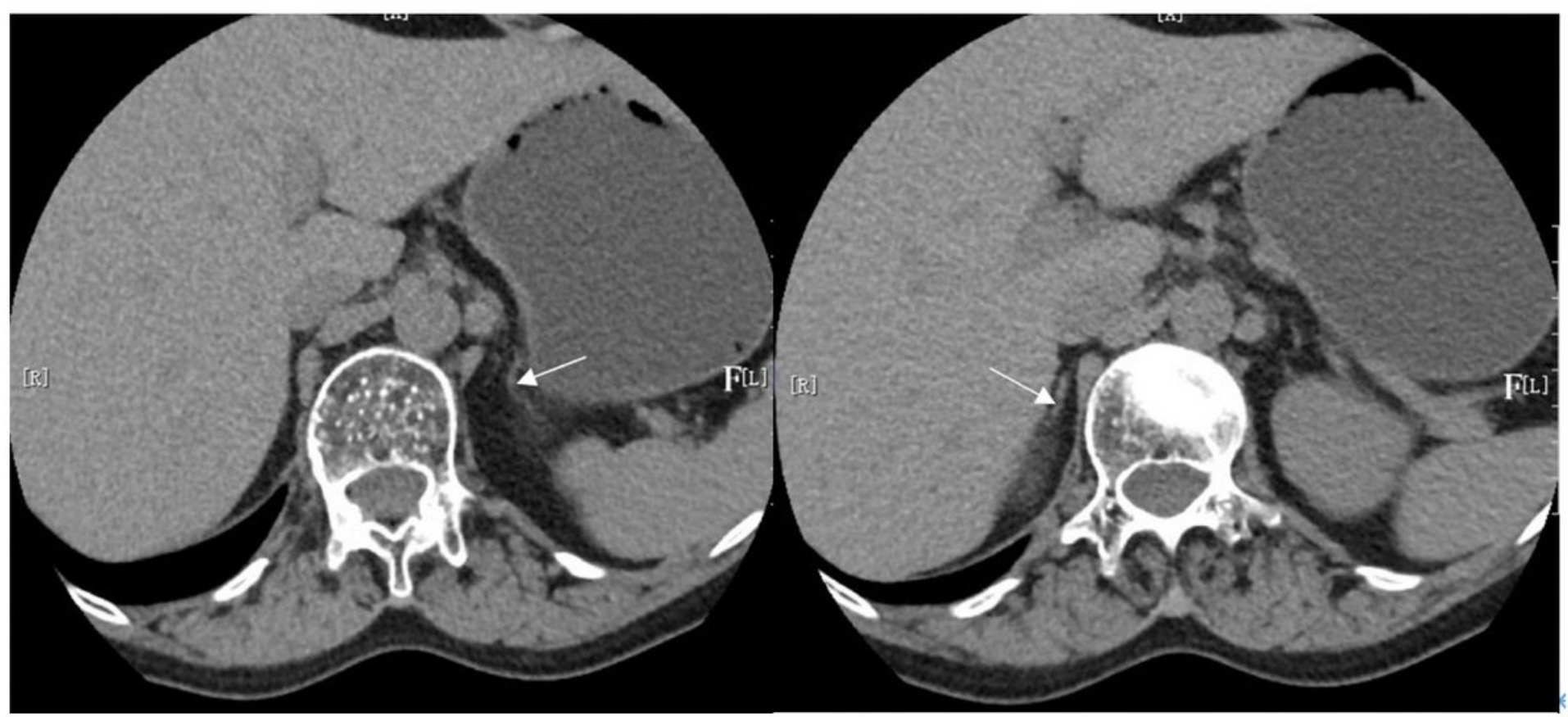


Figure 2

Abdominal CT scan of the patient with AHC. The white arrow showed the adrenal glands on both sides were small and structure was unclear.

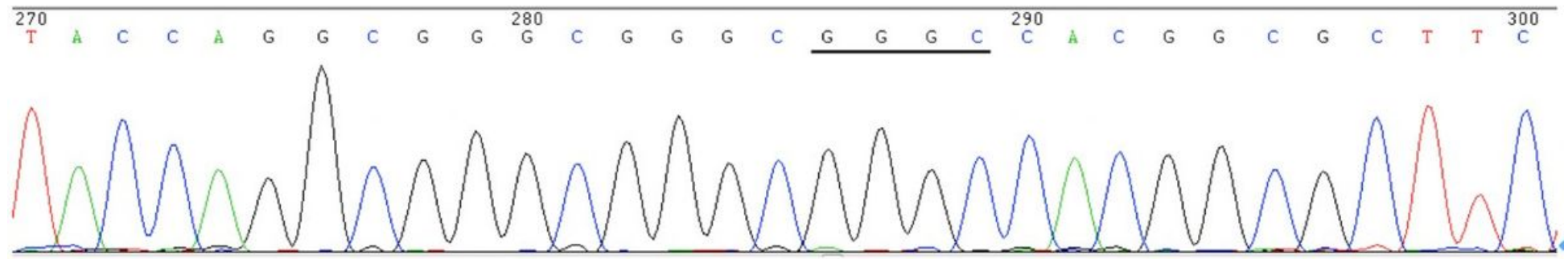

\section{Figure 3}

Sequencing traces of the mutation in NR0B1 gene. A homozygous c.572_575dup insertion in exon 1 of NR0B1, resulting in a frameshift p.Thr193GlyfsX13.

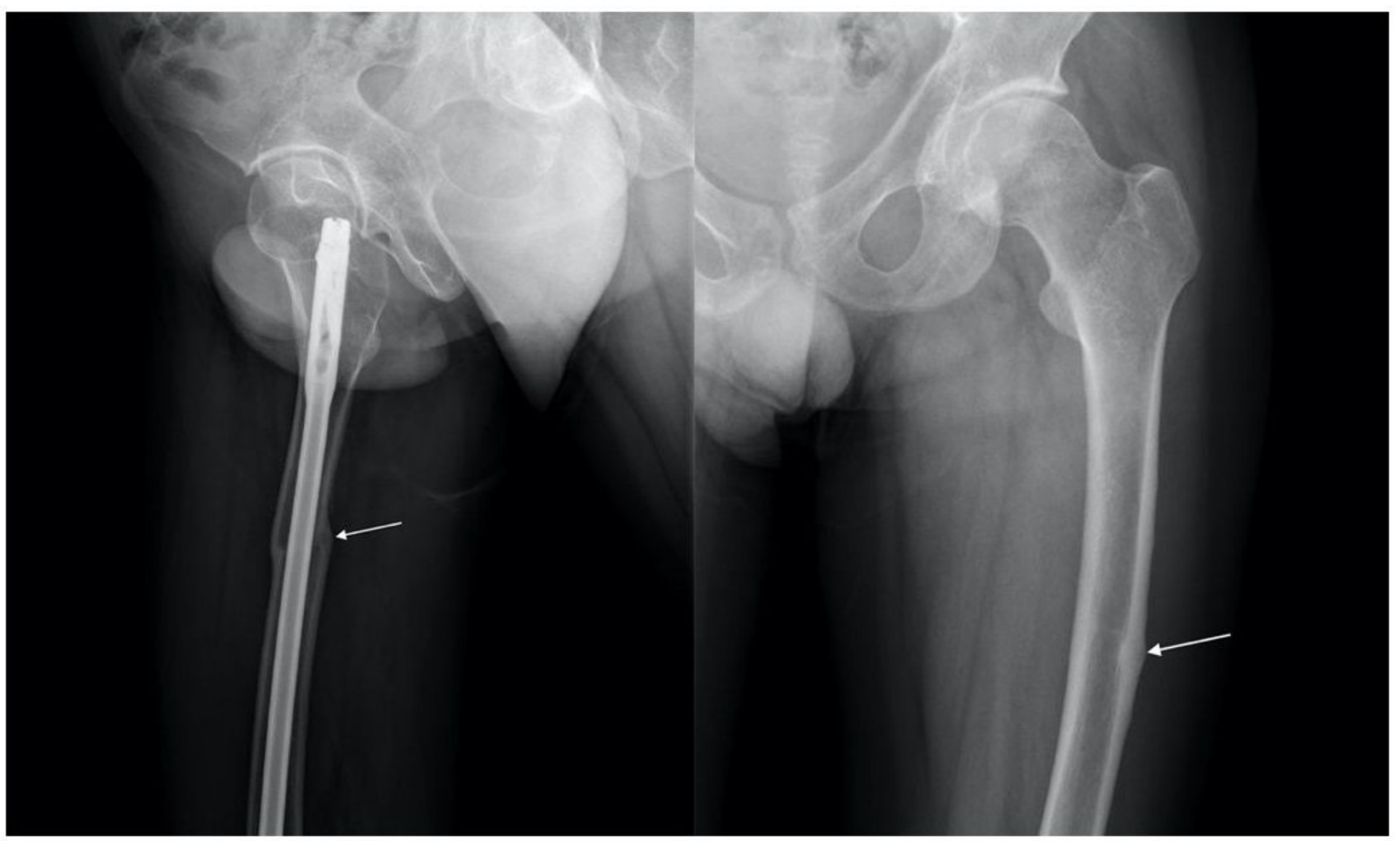

Figure 4

Radiographs of bilateral femurs. 4A White arrow showed internal fixation of right femoral shaft fracture. 4B White arrow showed atypical fracture in the right femur. 